\title{
Introduced populations of the garden lupine are adapted to local generalist snails but have lost alkaloid diversity
}

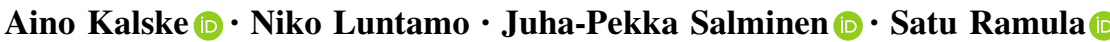

Received: 17 March 2021 / Accepted: 15 August 2021 / Published online: 28 August 2021

(C) The Author(s) 2021

\begin{abstract}
Intraspecific variation in growth and defence among plant populations can be driven by differences in (a)biotic conditions, such as herbivory and resources. Introduction of species to novel environments affects simultaneously herbivory encountered by a plant and resource availability both directly and via altered competitive environment. Here, we address the question of how growth (leaf mass per area (LMA), plant size) and resistance traits (leaf alkaloids, leaf trichomes, resistance to a generalist snail) vary and covary between native and introduced populations of the garden lupine, Lupinus polyphyllus. We focused specifically on evolved differences among populations by measuring traits from plants grown from seed in a common environment. Plants from the introduced populations were more resistant against the generalist snail, Arianta arbustorum, and they had more leaf trichomes and higher LMA than plants from the native populations. The composition of alkaloids differed
\end{abstract}

Supplementary Information The online version contains supplementary material available at https://doi.org/10.1007/ s10530-021-02622-4.

A. Kalske $(\bowtie) \cdot$ S. Ramula

Department of Biology, University of Turku, Turku, Finland

e-mail: amkals@utu.fi

N. Luntamo $\cdot$ J.-P. Salminen

Natural Chemistry Research Group, Department of

Chemistry, University of Turku, Turku, Finland between native and introduced populations, with the native populations having more diversity in alkaloids among them. Resistance was positively associated with plant size and LMA across all populations. Other trait associations differed between native and introduced areas, implying that certain trade-offs may be fundamentally different between native and introduced populations. Our results suggest that, for the introduced populations, the loss of native herbivores and the alterations in resource availability have led to a lower diversity in leaf alkaloids among populations and may facilitate the evolution of novel trait optima without compensatory trade-offs. Such phytochemical similarity among introduced populations provides novel insights into mechanisms promoting successful plant invasions.

Keywords Herbivory $\cdot$ Specialised plant metabolites $\cdot$ Trade-offs $\cdot$ Resistance $\cdot$ Lupinus polyphyllus

\section{Introduction}

Herbivory of plant tissues is an ordinary sight that, nonetheless, can have substantial negative effects on the growth and fitness of an individual plant (Belsky 1986; Turcotte et al. 2014). Because of these negative effects, herbivores can select for traits that protect 
plants from being eaten, such as chemical and physical defences (Agrawal et al. 2012; Kessler and Kalske 2018). As a result of their negative fitness impacts, herbivores are recognised as major drivers of plant genetic and phenotypic diversity at different levels of biological organisation, from among species to among and within populations (Futuyma and Agrawal 2009; Gloss et al. 2013). For example, spatial variation in herbivory can explain intraspecific patterns in herbivore defences among populations (Toju and Sota 2006; Muola et al. 2010). However, plant defence allocation can be limited or modified by abiotic factors, as postulated by the plant resource availability hypothesis (Coley et al. 1985). Therefore, the negative impact of herbivory on a plant depends not only on the amount or type of damage, but also on resource availability (Hawkes and Sullivan 2001). Variation in both herbivory and resources can thus interact to determine the spatial patterns of intraspecific variation in plant defence phenotypes and genotypes (Woods et al. 2012; Burghardt 2016).

Plant traits do not evolve independently of one another, but often exhibit patterns of covariation. Genetically based trait associations among populations can represent adaptive trait complexes where selection has favoured combinations of genetically independent traits (Armbruster and Schwaegerle 1996). Alternatively, trait covariation may arise from genetic constraints, if the same gene affects multiple traits simultaneously (pleiotropy) (e.g., Arnold 1992). The direction (positive/negative) of the among-population covariance can depend on large-scale patterns of environmental factors, in which, for example, variation in latitude and/or altitude determine broad-scale differences in the direction of selection (Jonas and Geber 1999; Anstett et al. 2016). To determine which trait associations are more flexible, and which are more fixed, it is necessary to explore trait associations among populations that experience considerably different environmental conditions.

When species spread to novel areas, multiple facets of the environment are in flux, from ecological interactions to the abiotic environment and, hence, resource availability (Alpert et al. 2000). Therefore, compared to native conspecifics, introduced populations can experience selection that favours novel trait optima and alters longstanding trait associations (Blossey and Notzold 1995). The direct herbivory encountered by an introduced plant often decreases, as novel environments typically lack most of the specialist herbivores that are adapted to feed on a species (Keane and Crawley 2002). Introduced species are thus hypothesised to experience selection to decrease their investment in defences and instead allocate those resources for growth-promoting traits, giving them an advantage in competition against native species (evolution of increased competitive ability; EICA; Blossey and Notzold 1995). Improved competitive ability could then allow them to acquire a larger share of the available resources compared to competitors, potentially further reducing the investment in defence (Goldberg 1996). Alternatively, larger plants may be able to invest more in defence, or an effective defence could yield the plant a competitive advantage, which would result in a positive association between defence and plant size (Hahn et al. 2019). Finally, the effects of species introductions to novel areas on selection for defence can depend on the type of herbivory: plants in the introduced populations may encounter more generalist herbivory than in the native populations, leading not to loss of defence, but instead a shift towards higher defence to generalist herbivores (shifting defence hypothesis; Müller-Schärer et al. 2004; Joshi and Vrieling 2005).

In this study, we explore plant resource allocation between growth and herbivore resistance traits in native (USA) and introduced (Finland) populations of the perennial herb Lupinus polyphyllus (Lindl., Fabaceae). We combined common-garden experiments with field observations of herbivory to investigate the role of herbivores in shaping growth (leaf mass per area and plant size) and putative resistance traits (diversity/concentration of leaf alkaloids, density of leaf trichomes, and resistance to the generalist land snail Arianta arbustorum, L.). Leaf mass per area (LMA) describes a plant's investment in leaves and has been identified as a key trait in plant 'leaf economics' (Wright et al. 2004), but it is also sometimes related to leaf palatability to herbivores (Schädler et al. 2003; Hanley et al. 2007). Quinolizidine alkaloids are specialised metabolites found mostly within the Fabaceae family, which are generally thought to protect plants from herbivory (Wink 2019). Leaf trichomes have a function in leaf antiherbivore defences (Mauricio and Rausher 1997) as well as in leaf ecophysiology and abiotic stress tolerance through their modifications of the boundary 
layer of the leaf (Ehleringer et al. 1976; Sandquist and Ehleringer 2003).

Our goal was to address the question: Do native and introduced populations differ in 1) the level of herbivore damage in situ, 2) resistance traits (leaf alkaloids, leaf trichomes, resistance to a generalist snail), 3) plant growth traits (LMA, plant size), and 4) the trait associations between growth and resistance traits? We measured growth and resistance traits in a common environment allowing us to explore the evolutionary divergence between native and introduced populations in these traits. We predicted that plants in the native populations would experience higher levels of herbivore damage in situ than those in the introduced populations. As the introduced plants of L. polyphyllus are larger than those originating from the native population (Ramula and Kalske 2020), we predicted that-based on the growth-defence tradeoff-they would invest less in defences than the plants from the native range. Because both leaf trichomes and LMA typically increase with the intensity of solar irradiation and temperature (Ehleringer et al. 1976; Wright et al. 2004; Agrawal et al. 2009), we predicted these traits would be higher in the plants from the lower-latitude native range. Finally, in plants from the introduced populations, we expected to find fewer negative trait associations, i.e. trade-offs, because of weaker selection pressure from herbivores.

\section{Materials and methods}

\section{Study species}

Garden lupine, Lupinus polyphyllus, is a short-lived perennial herb native to western North America. It has been introduced and has become invasive in Europe, southern Australia, New Zealand, and Chile (Fremstad 2010; Meier et al. 2013). The species was brought to Europe as an ornamental plant and in Finland it was first recorded to have escaped from gardens in the late 1800s (Fremstad 2010). In Finland, it negatively affects vascular plant diversity and species richness across all habitat types where it occurs (Valtonen et al. 2006; Ramula and Pihlaja 2012) as well as reduces total arthropod numbers by nearly $50 \%$ and alters their community composition (Ramula and Sorvari 2017). In its native range, L. polyphyllus grows in moist meadows and riverbanks (Beuthin 2012), whereas in
Finland it commonly occurs in road verges, wastelands, and forest understories (Fremstad 2010). The species hosts a diverse community of insect herbivores in its native range, including aphids, leaf miners, true bugs, fly larvae, and lepidopteran caterpillars (A. Kalske, personal observation). In Finland, some generalist insects are occasionally observed to feed on it (i.e. the lepidopteran caterpillars Amphipyra pyramidea and Vanessa cardui) but most damage is typically inflicted by mollusc herbivores (S. Ramula, personal observation).

We used the hermaphroditic land snail Arianta arbustorum (Helicidae) as a generalist herbivore in this study. The species occurs from central to northern Europe (Terhivuo 1978; Buria and Stahel 1983) and prefers habitats with rich and dense vegetation. It feeds broadly on live and decaying plant material, wilted flowers, mushrooms, arthropods, and soil (Terhivuo 1978; Speiser and Rowell-Rahier 1991), including fresh leaves of L. polyphyllus in Finland (S. Ramula, personal observation). Arianta arbustorum is sensitive to pyrrolizidine alkaloids and its feeding tends to decrease with increasing pyrrolizidine alkaloid content of the plant, at least when feeding on the perennial plant Adenostyles alliariae (Speiser and Rowell-Rahier 1991).

Field herbivory and seed collection

We collected seeds from 16 putative populations of $L$. polyphyllus in its native range in the western United States (CA, OR) and from 16 introduced populations in Finland in the summer of 2018. However, DNA barcoding confirmed the species identity for only 11 of the native populations (Ramula and Kalske 2020). Due to poor seed germination of the remaining populations (see below), we were left with 6 native and 16 introduced populations (Online resource, Table S1). Populations in the native range generally inhabited lower latitudes and higher altitudes than the introduced populations. Based on climate data from 1970-2000, mean annual precipitation is higher in the native compared to the introduced range, but mean annual temperatures do not differ between the populations in the two countries (Ramula and Kalske 2020). The mean distance between the six remaining populations in the USA was $203 \mathrm{~km}$ (range 13-516 km) and in Finland $213 \mathrm{~km}$ (range 1-441 km). In late July, we collected seed pods separately from 20 individuals 
and estimated herbivory on L. polyphyllus by examining herbivore damage on all the full-grown individuals in three randomly placed 50 by $50 \mathrm{~cm}$ quadrats in each population. For each plant in the quadrat, we scored the plant damage level from 0 to 3 , with 1 being $<40 \%$ of leaves damaged, 2 being $40-60 \%$ leaves damaged, and 3 being $>60 \%$ leaves damaged. The mean number of individuals assessed for herbivore damage in each population was seven. We also noted the presence of different types of herbivory, which included leaf-mining, -chewing, and -sucking herbivores, aphids, and snails, and counted the number of snails found in each quadrat. Snails were only found in the Finnish populations, whereas insect herbivores were only observed in the native populations.

\section{Growth and resistance traits}

To assess the differentiation in growth and resistance traits between native and introduced populations of $L$. polyphyllus, we grew plants from seed from all the populations in a common environment at the Ruissalo Botanical Garden of the University of Turku, Finland (N 60.43 ${ }^{\circ}$, E $\left.22.18^{\circ}\right)$. In January 2019, seeds from each maternal plant were scarified by nicking the seed coat with a scalpel prior to planting in plug trays with growth medium (brand Kekkilä, product Taimimulta). We grew the plants in a temperature- and lightcontrolled greenhouse with $16 \mathrm{~h} / 8 \mathrm{~h}$ light and $15^{\circ}$ $12{ }^{\circ} \mathrm{C}$ temperature day/night cycle. At the cotyledon stage, one seedling per maternal plant was moved to $8 \times 8 \mathrm{~cm}$ pots filled with commercial potting medium (brand Kekkilä, product Karkea ruukutusseos, mildly fertilized with NPK). We excluded 5 out of 11 native populations from further experiments because of poor germination, despite efforts to germinate more seeds at a later date (on average only five seedlings per population survived) resulting in 6 native populations included in the study.

We sampled leaves for analyses of quinolizidine alkaloids starting at six weeks after planting, once the first set of plants had three fully expanded true leaves. We sampled up to 10-14 individuals per population (mean $=13$ plants, a total of 291 plants; Online resource, Table S1), with each individual coming from a different maternal plant. We checked the plants weekly for three weeks and sampled them as they reached the appropriate size. The time between the first and last sampling date was two weeks, although the majority of plants were sampled in the first two sampling days (267 out of 291). Sampling date did not affect the total leaf alkaloid content $\left(F_{1,289}=0.34\right.$, $P=0.560)$. We excised the three largest adjacent leaflets from each of the three open leaves with a sharp blade, and stored them in paper bags at $-20{ }^{\circ} \mathrm{C}$ until drying. We freeze-dried the leaves for $48 \mathrm{~h}$, then ground them to a fine powder with a ball mill and weighed $10 \pm 0.5 \mathrm{mg}$ of the material into glass sample tubes for alkaloid analyses (see below).

We measured leaf mass per area $\left(\mathrm{mg} \mathrm{cm}^{-2}\right.$; LMA) and trichome density from a sample of three leaf discs (diameter: $9 \mathrm{~mm}$ ) per plant. We removed each disc from a separate leaflet, close to the tip of the leaflet to avoid the leaf vein; this was carried out at the same time as sample collection for alkaloid analyses. We dried and weighed the leaf discs to the nearest $0.1 \mathrm{mg}$ to obtain a measure of LMA and counted the number of trichomes on the underside of the leaf disc. We used the mean of the three discs for both traits in further analyses. LMA values and trichome number were transformed to correspond to leaf mass in $\mathrm{mg}$ per $\mathrm{cm}^{2}$ to enable comparison with other studies.

In May, we transferred the plants to larger 1-L pots and moved them to an outside common garden. Plants were watered regularly during the growing season, but they did not receive any fertiliser. In late May, when plants were still at the vegetative stage, we measured plant height to the tip of the tallest leaf $(\mathrm{cm})$ and diameter at the base $(\mathrm{cm})$ as an estimate of plant size. Plant size in May correlated with plant size in June $(\mathrm{N}=286, \quad \mathrm{r}=0.32, \quad P<0.001)$ and in August $(\mathrm{N}=284, \mathrm{r}=0.33, P<0.001 ; \mathrm{N}$ was smaller than at the beginning of the experiment because not all plants survived).

To estimate resistance to generalist herbivores, we conducted a bioassay in June with A. arbustorum land snails, which we had previously observed feeding on L. polyphyllus in Finland. We collected full-grown $A$. arbustorum locally two days prior to the bioassay. Snails were kept at room temperature in 5-L plastic buckets (ca. 100 snails per bucket) with dandelion (Taraxacum sp.) leaves for food ad libitum. Twentyfour hours prior to the bioassay, we selected the snails to be used, measured their shell width, and placed them in individual plastic containers $(125 \mathrm{~mL}$, diameter $10 \mathrm{~cm}$ ) without food, with a sheet of moist paper towel for humidity. We kept the snails in a growth chamber at $18{ }^{\circ} \mathrm{C}$ without light. In the bioassay, we 
excised one leaflet of a fully expanded, healthy leaf, which we then offered to a snail, one leaflet per snail. We allowed the snails to feed on the leaves for $6 \mathrm{~h}$ at $18{ }^{\circ} \mathrm{C}$ in darkness. To obtain a measure of the leaf area consumed by each snail, we photographed the leaves before and after the bioassay, measured their areas $\left(\mathrm{cm}^{2}\right)$ with LeafByte (Getman-Pickering et al. 2020), and calculated the difference in leaf area, which we then used as an inverse estimate of resistance. We repeated the bioassay in August, but we were not able to use as many plants as in June because of a heavy infestation of powdery mildew. The results from the two bioassays were highly correlated (Pearson correlation between population averages of leaf area removed in June and August $\mathrm{n}=22, \mathrm{r}=0.692$, $P=0.001)$. Therefore, we used only the data obtained in the June bioassay.

\section{Alkaloid analysis}

To extract alkaloids, we first added $5.0 \mathrm{~mL}$ chloroform to ground leaf powder. Samples were shaken at $260 \mathrm{rpm}$ with a planar shaker for $10 \mathrm{~min}$ and macerated overnight at $+4{ }^{\circ} \mathrm{C}$. After maceration, samples were shaken at $260 \mathrm{rpm}$ for $10 \mathrm{~min}$, sonicated with a Marshall Scientific (Hampton, NH, USA) Branson 5510 sonicator for $30 \mathrm{~min}$, and centrifuged at $5000 \mathrm{rpm}$ for $5 \mathrm{~min}$. We pipetted $400 \mu \mathrm{l}$ of extract into an Eppendorf tube and evaporated it in vacuo with an Eppendorf Concentrator plus (Eppendorf AG, Hamburg, Germany). The residue was dissolved in $1500 \mu \mathrm{l}$ of $5 \mathrm{mM} \mathrm{HCl}$ solution. All samples were filtered using a PTFE syringe filter $(4 \mathrm{~mm}, 0.2 \mu \mathrm{m}$, Thermo Fisher Scientific Inc., Waltham, MA, USA) and pipetted into a 96-well plate for UHPLC-DADHESI-Orbitrap analysis. Samples were analysed using an ultra-high performance liquid chromatograph coupled with a photodiode array detector (UHPLC-DAD, Acquity UPLC, Waters Corp., Milford, MA, USA) and a hybrid quadrupole-Orbitrap mass spectrometer (Q Exactive, Thermo Fisher Scientific GmbH, Bremen, Germany). We used a Waters Aquity UPLC BEH phenyl column $(1.7 \mu \mathrm{m}, 2.1 \times 30 \mathrm{~mm}$, Waters Corp., Wexford, Ireland). In the UHPLC, the mobile phase consisted of acetonitrile (A) and $0.1 \%$ aq. formic acid (v:v) (B) and the elution profile was as follows: 0-0.1 $\mathrm{min} 3 \% \mathrm{~A}$ in $\mathrm{B}$ (isocratic), 0.1-3.0 $\mathrm{min}$ $3-45 \%$ A in B (linear gradient), 3.0-3.1 min 45-90\% $\mathrm{A}$ in $\mathrm{B}$ (linear gradient), 3.1-4.2 min column wash and stabilisation. Flow rate was $0.65 \mathrm{~mL} \mathrm{~min}^{-1}$. The heated ESI source (H-ESI II, Thermo Fisher Scientific $\mathrm{GmbH}$, Bremen, Germany) was operated in positiveion mode. The parameters were set as follows: spray voltage, $+3.8 \mathrm{kV}$; sheath gas $\left(\mathrm{N}_{2}\right)$ flow rate, 60 (arbitrary units); aux gas $\left(\mathrm{N}_{2}\right)$ flow rate, 20 (arbitrary units); sweep gas flow rate, 0 (arbitrary units); capillary temperature, $+380{ }^{\circ} \mathrm{C}$. A full scan at range $m / z$ 90-500 and the TopN stepped normalised collision energy (NCE) method were used for quantification and identification of alkaloids, respectively. Insource collision-induced dissociation energy was $20 \mathrm{eV}$ and collision energies of 20,50 , and $80 \mathrm{eV}$ were used in the higher-energy collisional dissociation (HCD) cell. Mass spectrometric data were recorded from 0 to $3.0 \mathrm{~min}$. We identified alkaloids by measuring the exact mass of compounds. We used Xcalibur software to integrate extracted ion chromatograms (EIC) of known $\mathrm{m} / \mathrm{z}$ values of the identified alkaloids. Integrated peak areas were converted into concentrations $\left(\mu \mathrm{g} \mathrm{mL}^{-1}\right)$ using five external calibration compounds: sparteine by Sigma-Aldrich and lupanine, tigloyloxylupanine, benzoyloxylupanine, and cinnamoyloxylupanine purified from L. polyphyllus leaves. Calibration curves were prepared by making dilutions of known concentrations (sparteine $1.00-100.00 \mu \mathrm{g} \mathrm{mL}^{-1}$, lupanine 1.02-102.00 $\mu \mathrm{g} \mathrm{mL}^{-1}, \quad$ tigloyloxylupanine 1.03-103.00 $\mu \mathrm{g} \mathrm{mL}^{-1}, \quad$ benzoyloxylupanine $1.00-100.00 \mu \mathrm{g} \mathrm{mL}^{-1}$, and cinnamoyloxylupanine 1.02-102.00 $\mathrm{g} \mathrm{mL}^{-1}$ ). Altogether, we quantified 23 quinolizidine alkaloid compounds or compound isomers from the leaves, in $\mathrm{mg} \mathrm{g}^{-1} \mathrm{DW}$ (Table 1; Online resource, Figure S1, S2).

\section{Data analyses}

We conducted all analyses in $\mathrm{R}$ ( $\mathrm{R}$ version 3.5.2; $\mathrm{R}$ Core team 2018). We compared the level of herbivore damage observed in situ between the two countries based on population-level herbivore damage scores from the field. We then tested the difference in herbivore damage with a t-test (stats::t.test) with the average damage score in each population $(\mathrm{N}=22)$ as a response variable and country as an explanatory variable.

To examine differences in leaf alkaloid composition between the two countries, we first performed a non-metric multidimensional scaling (NMDS) 


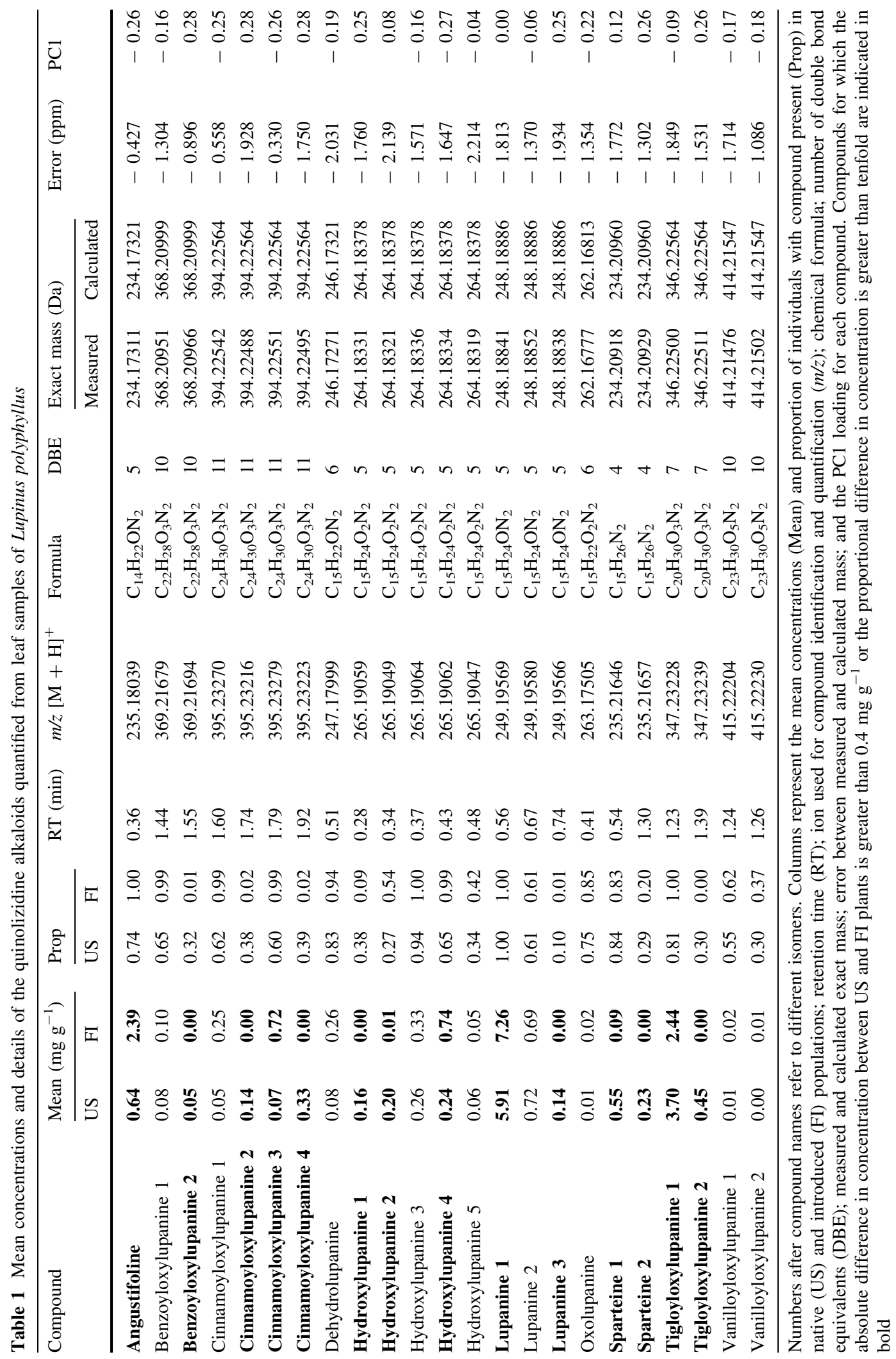


analysis with the 23 quinolizidine alkaloid compounds or compound isomers (vegan::metaMDS; Oksanen et al. 2019). We used a Bray-Curtis dissimilarity matrix (vegan::vegdist), with Wisconsin double standardisation and two dimensions (stress $=0.171$ ) for the ordination. We tested whether country of origin affected alkaloid composition with permutational multivariate analyses of variance (PERMANOVA; 999 permutations, vegan::adonis) and determined whether it affected alkaloid variability with a test of multivariate group dispersion (vegan::betadisper). This latter measure has been adopted as a measure of beta diversity in community ecology (Anderson et al. 2006). Because it was not possible to control for the non-independence of observations at the population level, we then performed an NMDS (Bray-Curtis dissimilarity, Wisconsin double standardisation, two dimensions, stress $=0.053$ ), a PERMANOVA (999 permutations), and a comparison of multivariate group dispersion with population means. We again tested for the effect of country on the composition and diversity (multivariate group dispersion) of alkaloids. Finally, we tested for the effect of country on the total concentration of leaf alkaloids and alkaloid richness with a linear mixed-effects model and restricted maximum likelihood estimates (lme4::Imer; Bates et al. 2015, and lmerTest::anova; Kuznetsova et al. 2017). Both variables were square-root transformed to normalise residuals. We included country as a fixed effect and population as a random effect in both models. We estimated the degrees of freedom using the Kenward-Roger method.

Similarly, to investigate the effect of country of origin on growth and resistance traits, we constructed mixed-effects models with restricted maximum likelihood, with country as a fixed effect and population as a random effect. We used the leaf area eaten $\left(\mathrm{cm}^{2}\right.$; square-root transformed), density of trichomes on the underside of the leaf (number of trichomes $\mathrm{cm}^{-2}$; square-root transformed), LMA ( $\mathrm{mg} \mathrm{cm}^{-2}$ ), and plant size (height $\times$ base radius in $\mathrm{cm}$ ) as response variables. For the analysis of leaf area eaten, we included snail size (shell width) as a covariate and excluded snails that did not consume anything (63 snails, remaining $\mathrm{N}=232$ ). For the analysis of plant size, we included seed mass as a covariate. We then quantified how much of the trait variability is explained by country and population by calculating marginal and conditional $R^{2}$ values for each trait
(MuMIn::r.squaredGLMM; Bartón 2020). To ensure that the differences between countries were not due to the unbalanced numbers of populations, we obtained bootstrapped means and $95 \%$ confidence intervals (CI) for the two countries for each of the linear mixed models, with 1000 replications using the percentile method.

We then explored variation and covariation in growth and resistance traits by conducting a series of linear models. First, to obtain population-level values describing leaf alkaloid composition, we conducted a principal component analysis for all 23 quantified alkaloids using the scaled population means of alkaloid values (vegan::rda). We extracted the population scores for the first principal component to be used in the analyses (Alkaloid PC1). PC1 explained 39\% of the variation observed in alkaloid composition and was most strongly positively associated with cinnamoyloxylupanine 2 and 4, benzoyloxylupanine 2, and tigloyloxylupanine 2, and negatively associated with cinnamoyloxylupanine 1 and 3 , angustifoline, and hydroxylupanine 3 (Table 1). Other traits we included in the analyses were population mean values for resistance (calculated as 0-leaf area consumed, to have increasing resistance with increasing trait values), LMA, leaf trichomes, and plant size (square-root transformed). All independent variables except for alkaloid PC1 were centred by subtracting the mean value from the trait value. We initially used each trait as a response variable with all the other traits as explanatory variables (stats:: $1 \mathrm{~m}$, car::Anova). We also included interactions of each trait with country to test whether trait associations differ between the introduced and the native populations. Because plant size was confounded with country, we excluded it as an explanatory variable from all analyses and only modelled it as a response variable. We used backward model selection based on comparison of AIC values (stats::step) to determine the variables in the final models.

\section{Results}

We first explored the differences in herbivory in situ between native and introduced populations. Individuals of Lupinus polyphyllus were more damaged by herbivores in the native populations than in the introduced populations (mean \pm SE field herbivory 


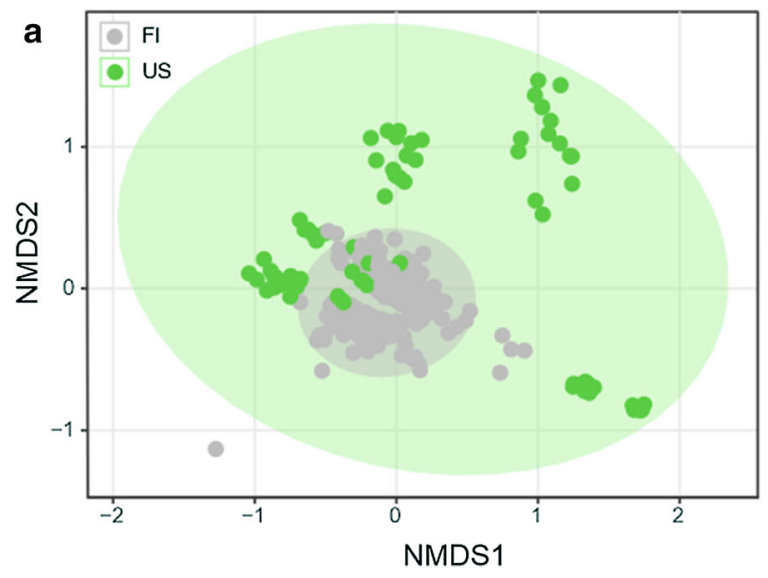

Fig. 1 NMDS ordination based on leaf alkaloid concentrations in individual plants of Lupinus polyphyllus in the greenhouse. Differences (A) between native (US) and introduced (FI) populations and (B) among US populations. Panels are based on the same ordination, but only plants and populations from the US are displayed in B because plants from FI populations cluster on top of each other. Ellipses display $95 \%$ confidence intervals

score: US $2.52 \pm 0.25 ;$ FI $0.81 \pm 0.10 ; \mathrm{t}=-6.26$, df $=6.62, P=0.001)$.

We then examined differences in leaf alkaloid content as well as in other resistance and growth traits between the two countries. All 23 quantified quinolizidine alkaloids or alkaloid isomers were present in plants from both the native and introduced populations, although eight compounds that were present in plants from the US were rare or only present in trace amounts in the FI plants (Table 1; Online resource, Figure S2). Leaf alkaloid composition differed between countries both when modelled at the level of individual plants $\left(F_{1,289}=22.9, \quad P=0.001\right.$, $\mathrm{R}^{2}=0.07$; Fig. 1A) and based on population means $\left(\mathrm{F}_{1,20}=4.7, P=0.007, \mathrm{R}^{2}=0.19\right)$. On average, concentrations of lupanine isomer 1 were higher in plants from Finland compared to those from the US (Table 1), and although lupanine isomers 2 and 3 were present in higher concentrations in the plants from the US, total concentrations of all three lupanine isomers combined were higher in plants from Finland (US $6.77 \pm 0.65 \mathrm{mg} \mathrm{g}^{-1}$, FI $7.95 \pm 0.38 \mathrm{mg} \mathrm{g}^{-1}$ ). Other compounds that were present in markedly higher concentrations in plants from Finland compared to the US were angustifoline, dehydrolupanine, hydroxylupanine isomer 4, and cinnamoyloxylupanine isomers 1 and 3 (Table 1). Both sparteine isomers 1 and 2 were present in higher concentrations in plants from the US

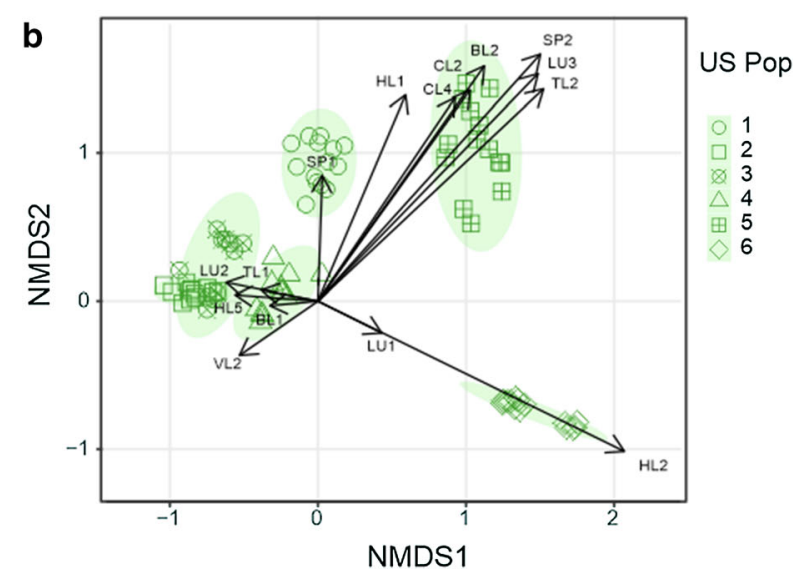

for countries (A) and for US populations (B). Arrows indicate compound scores for the NMDS. Eight compounds that were near the centre have been removed for clarity. Abbreviations for compound names in panel B): $L U$ lupanine, $S P$ sparteine, $C L$ cinnamoyloxylupanine, $T L$ tigloyloxylupanine, $H L$ hydroxylupanine, $V L$ vanilloyloxylupanine, $B L$ benzoyloxylupanine

than in plants from Finland (Table 1), and this difference was mainly driven by high concentrations of the compounds in US population 1 for isomer 1 and population 5 for isomer 2 (Fig. 1B; Online resource, Figure S2). Other compounds that were nearly unique to plants from the US were benzoyloxylupanine isomer 2, hydroxylupanine isomers 1 and 2, cinnamoyloxylupanine isomers 2 and 4, and tigloyloxolupanine isomer 2 (Table 1; Online resource, Figure S2). Overall, alkaloid composition was more diverse in the US plants compared to the Finnish plants (multivariate group dispersion among individuals $F_{1,289}=78.7, P<0.001$; populations $F_{1,20}=31.6$, $P<0.001)$. Total leaf alkaloid concentration $\left(F_{1,20}=0.68, \quad P=0.419\right)$ and alkaloid richness $\left(F_{1,20}=0.89, P=0.355\right)$ did not differ between plants from the US and Finland (Fig. 2A and B). Finnish plants of $L$. polyphyllus were nevertheless more resistant against the generalist snail A. arbustorum, as measured by leaf consumption $\left(F_{1,20}=17.6\right.$, $P<0.001$; Fig. 2C). They also had more leaf trichomes $\left(F_{1,20}=47.9, \quad P<0.001\right)$, higher LMA, $\left(F_{1,20}=7.3, \quad P=0.013\right)$, and they were larger $\left(F_{1,27}=16.5, P<0.001 ;\right.$ Fig. $\left.2 \mathrm{D}-\mathrm{F}\right)$ than plants from the US populations. Seed mass did not affect plant size $\left(F_{1,264}=0.00, P=0.954\right)$. Larger snails consumed more leaves than smaller snails $\left(F_{1,222}=32.8\right.$, $P<0.001)$. Marginal and conditional $R^{2}$ values 

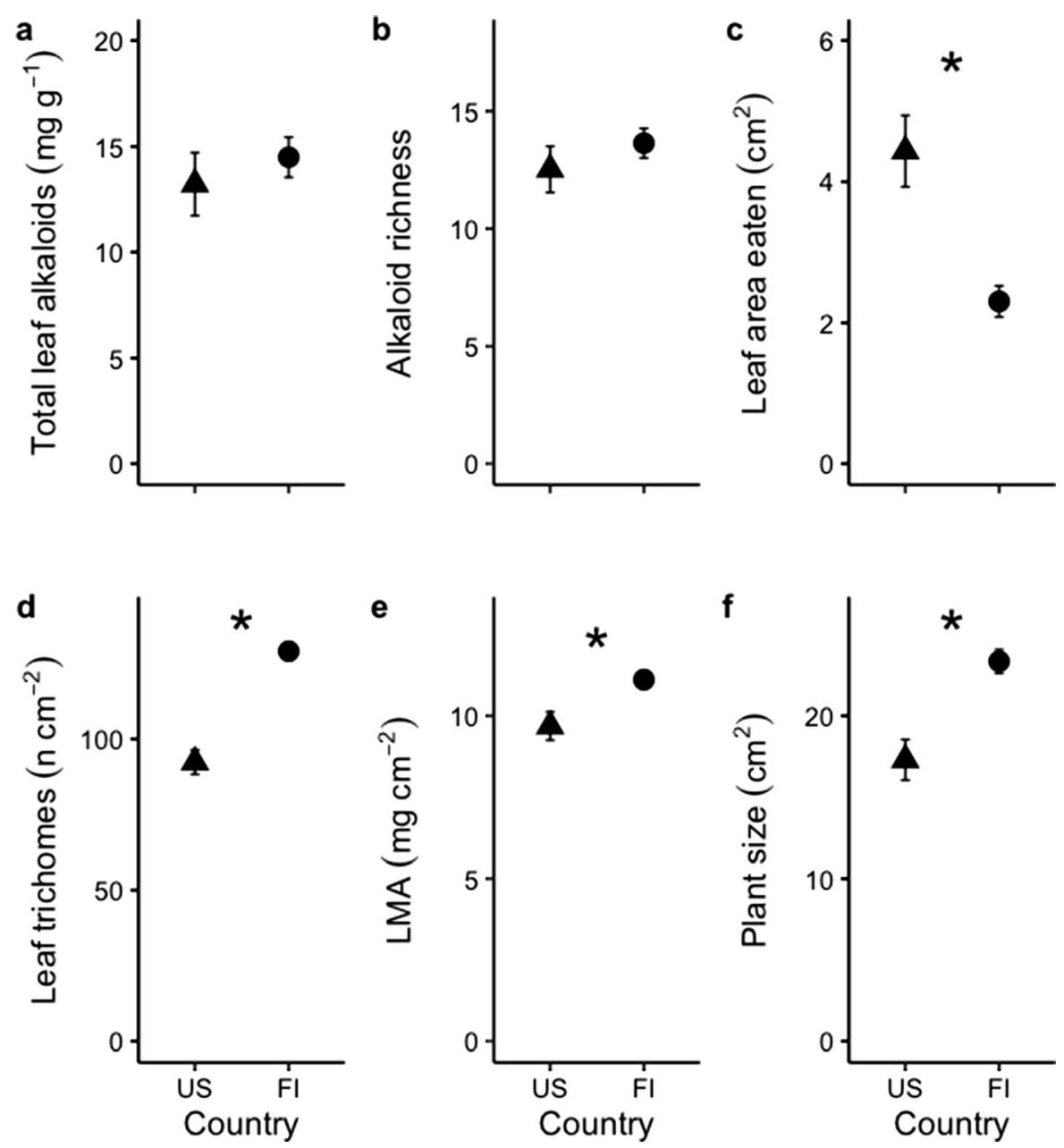

Fig. 2 Resistance (A-D) and growth (E, F) traits of Lupinus polyphyllus from native (US) and introduced (FI) populations grown in a greenhouse/common garden. Values are backtransformed estimated marginal means \pm standard error. Plant

revealed that population explained a notable proportion of the variation in most of the traits, but especially in alkaloid richness (Online resource, Table S2). Nonoverlapping $95 \%$ CIs from the bootstrapped data confirmed the differences in growth and resistance traits between countries (Online resource, Figure S3).

Finally, we explored the differences in trait associations among populations. There was an overall positive association between plant size and resistance (coefficient 2.24) as well as between LMA and resistance (coefficients 0.60 and 0.51 , with resistance and LMA as response variables, respectively; Table 2). Trait associations differed between the introduced and native populations in the case of four trait pairs. There size was measured as height $\times$ base radius in $\mathrm{cm}$. An asterisk denotes a significant difference between countries $(P<0.05$, a linear mixed model)

was a slight positive association between plant size and leaf trichomes among the US populations, while these traits were slightly negatively associated among the populations from Finland (Fig. 3A). Among the US populations, there was a negative trait association, indicative of a trade-off, between alkaloid PC1 and resistance, and between alkaloid $\mathrm{PC} 1$ and leaf trichomes (Fig. 3B, C). Finally, leaf trichomes were positively associated with LMA only among the US populations (Fig. 3D). 
Table 2 Results from general linear models testing for trait associations among five traits, and differences in those trait associations between native and introduced populations of Lupinus polyphyllus

\begin{tabular}{|c|c|c|c|c|c|c|c|c|c|c|c|}
\hline \multirow[b]{2}{*}{ Explanatory variables } & \multirow[b]{2}{*}{ Df } & \multicolumn{2}{|c|}{ Plant size } & \multicolumn{2}{|c|}{ Alkaloid PC1 } & \multicolumn{2}{|c|}{ Resistance } & \multicolumn{2}{|c|}{ Trichomes } & \multicolumn{2}{|c|}{ LMA } \\
\hline & & $F$ & $P$ & $F$ & $P$ & $F$ & $P$ & $F$ & $P$ & $F$ & $P$ \\
\hline Country & 1 & 0.06 & 0.812 & 1.86 & 0.194 & 9.58 & 0.008 & 19.72 & 0.001 & 0.75 & 0.401 \\
\hline Alkaloid PC1 & 1 & - & - & & & 0.48 & 0.501 & 0.00 & 0.981 & 1.92 & 0.186 \\
\hline Resistance & 1 & 11.38 & 0.004 & 0.72 & 0.409 & & & 2.78 & 0.118 & 8.58 & 0.010 \\
\hline Trichomes & 1 & 0.42 & 0.526 & 0.17 & 0.683 & 2.18 & 0.162 & & & 0.64 & 0.437 \\
\hline LMA & 1 & 3.84 & 0.069 & 0.52 & 0.482 & 6.59 & 0.022 & 1.40 & 0.256 & & \\
\hline Alkaloid PC1 x Country & 1 & - & - & & & 3.89 & 0.069 & 1.78 & 0.204 & - & - \\
\hline Resistance $\mathrm{x}$ Country & 1 & - & - & 8.70 & 0.011 & & & 4.26 & 0.058 & 2.00 & 0.177 \\
\hline Trichomes x Country & 1 & 4.61 & 0.049 & 7.96 & 0.014 & 3.61 & 0.078 & & & 5.93 & 0.028 \\
\hline LMA x Country & 1 & 3.72 & 0.073 & 2.21 & 0.159 & 3.74 & 0.073 & 6.48 & $\mathbf{0 . 0 2 3}$ & & \\
\hline Residual Df & & 15 & & 14 & & 14 & & 14 & & 15 & \\
\hline
\end{tabular}

Explanatory variables that were removed from the model based on an AIC comparison are indicated with a dash (-) $P<0.05$ in bold
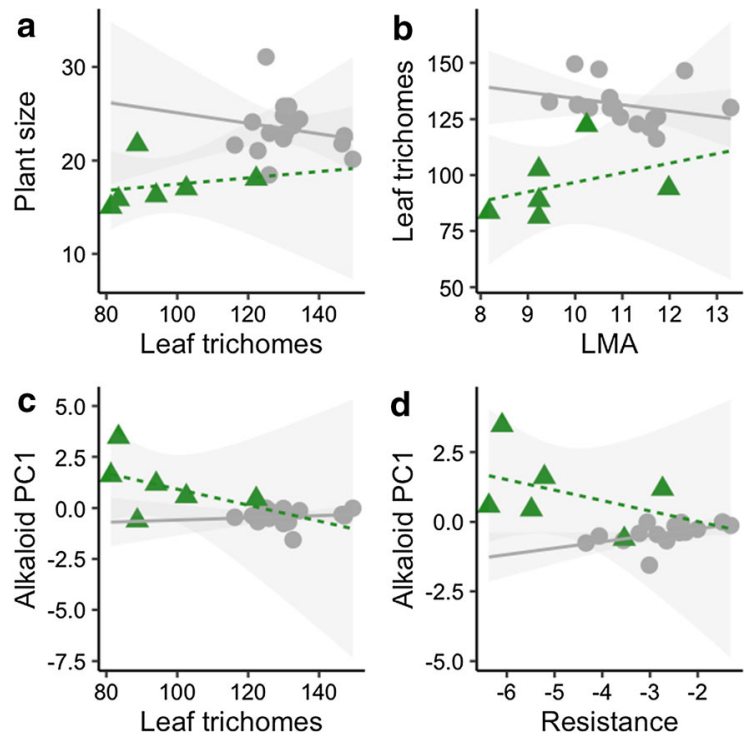

Fig. 3 Trait associations between growth and resistance traits measured at the population level for Lupinus polyphyllus in its native (US, green triangles, dashed line) and introduced (FI, grey circles, solid line) range. Resistance in panel $\mathrm{D}$ is measured as 0-leaf area consumed by the generalist land snail Arianta arbustorum

\section{Discussion}

The introduced populations of Lupinus polyphyllus in Finland encounter a different, less diverse suite of herbivores that overall cause less damage on the plants compared to those present in the native populations. Here, we report evolved differences between native and introduced populations of L. polyphyllus based on a study of growth (leaf mass per area (LMA), plant size) and herbivore resistance (leaf alkaloids, leaf trichomes, resistance to a generalist snail) in a common environment. We found that both growth and resistance traits were generally higher in plants from the introduced Finnish populations than in plants from the native North American populations, with the exception of leaf alkaloids, which were similar in total concentration and richness. Interestingly, we also observed dramatic among-population variation in alkaloid diversity in the native range, while the introduced populations were phytochemically alike. Such phytochemical similarity among introduced populations might be an indication of the lack of variability in biotic interactions in the introduced range that contributes to invasion success. In addition to these adaptive changes in individual traits in the introduced populations, many trait associations also differed between the native and introduced populations, thus providing evidence of altered selection pressures and differences in constraints on the response to selection between the two environments.

Given that alkaloids function as anti-herbivore agents (Wink 1988, 2019), we expected to see reduced allocation to these putative resistance mediating compounds in the introduced populations of $L$. 
polyphyllus. Although our results show that the composition and diversity of quinolizidine alkaloids in leaves are indeed different between the two places of origin, there were no differences in the total concentration of alkaloids or alkaloid richness. In contrast to the evolution of increased competitive ability hypothesis (Blossey and Notzold 1995), it appears there has not been selection to decrease the overall allocation to these compounds. The higher diversity of alkaloids in the native range is mainly due to unique and distinct chemotypes in some of the populations (Fig. 1B). The reason for the higher overall diversity could be the observed diverse herbivore community associated with $L$. polyphyllus in the US, as phytochemical diversity is generally associated with higher arthropod diversity (Richards et al. 2015) and abundance (Defossez et al. 2021). Meta-analyses of toxins in introduced and native plants have reported either higher levels of plant toxins in introduced populations (Doorduin and Vrieling 2011) or no difference between the two (Zhang et al. 2018). There is a growing body of evidence, however, pointing to the multiple functions of specialised metabolites, from UV protection and competition (Zheng et al. 2015) to nitrogen transport in the case of alkaloids (Wink and Witte 1984). These multiple roles could be one explanation for the persistently high level of leaf alkaloids in the introduced populations of L. polyphyllus. In addition, because leaf alkaloids in this study did not predict resistance to snails, it seems that their primary function in Finland is not the protection of plants against the novel generalist herbivore.

Interestingly, sparteine and lupanine, which are some of the best known and most well-studied alkaloids in lupines, displayed contrasting patterns in plants from the US and Finland, contributing to the difference in overall alkaloid composition we observed. Concentrations of lupanine isomer 1 and all lupanine isomers (1-3) combined were higher in plants from Finland, whereas sparteine isomers 1 and 2, along with tigloyloxolupanine isomers 1 and 2, were present in higher concentrations in the US plants (Table 1). Sparteine is more toxic to vertebrates than lupanine (Pothier et al. 1998) and both sparteine and tigloyloxolupanine are more effective antimicrobial agents than lupanine (Wink 1984). In addition to leaving behind native herbivores, introduced plants also likely experience shifts in the pathogens they encounter in the novel areas (Dawson and Schrama
2016). The observed changes in alkaloid composition towards those that have less anti-microbial potential could be due to the absence of selection pressure from coevolved pathogens in the introduced populations. Regardless of the mechanisms for the differences in alkaloid composition between the native and introduced populations, our results emphasise the importance of in-depth analysis of leaf chemistry when exploring the evolution of plant phytochemical defences.

Despite the lack of differences in total leaf alkaloid content or richness between countries, plants from the Finnish populations were more resistant against the generalist land snail A. arbustorum. This decoupling of toxic alkaloids and resistance was unexpected, as pyrrolizidine alkaloids in the plant Adenostyles alliariae negatively affected feeding of A. arbustorum (Speiser and Rowell-Rahier 1991), and phytochemical diversity can negatively affect herbivory (Glassmire et al. 2019). However, the resistance of Finnish plants to the snail is not surprising per se given that $L$. polyphyllus has had over 100 years to adapt to this generalist herbivore. Our result is in accordance with the shifting defence hypothesis, which suggests that selection in invasive plants leads to the evolution of higher resistance against generalist herbivores (Müller-Schärer et al. 2004; Joshi and Vrieling 2005). A meta-analysis of 32 invasive plant species showed that, indeed, resistance against generalist herbivores (measured as damage, similar to our study) was higher in plants from invasive populations, whereas the opposite was true for specialist herbivores (Zhang et al. 2018). Whether or not the results of the present study would be similar against a native specialist herbivore of L. polyphyllus remains an open question.

Finnish plants of L. polyphyllus were larger, had more leaf trichomes, and higher LMA than those originating from the native range. Although LMA tends to increase with the intensity of solar irradiation (Ehleringer et al. 1976; Wright et al. 2004; Agrawal et al. 2009), it also typically decreases with increasing water availability (Poorter et al. 2009). In its native range, L. polyphyllus inhabits wet meadows and river banks, and it is possible that lower LMA could reflect an adaptation to these mesic habitats. Evidence from other invasive plants is mixed: LMA was smaller in the perennial herb Ageratina adenophora in two different introduced areas compared to native populations (Feng et al. 2009), whereas in the perennial 
Bunias orientalis, plants from naturalised populations had higher LMA values than native ones (Tewes and Müller 2018). In general, LMA is positively correlated with cell-wall mass (Onoda et al. 2004) and with leaf toughness (Wright and Cannon 2001), which probably explains the positive association between resistance and LMA across all populations in our study. LMA was similarly negatively associated with herbivore load in another invasive plant, Bunias orientalis, suggesting that LMA may play an important role in resistance against herbivores in invasive plants more generally (Tewes and Müller 2018). Interestingly, we also found a positive association with plant size and resistance among populations, even though growth and resistance traits are typically observed to trade off in plants (Herms and Mattson 1992). These positive associations between resistance, LMA, and growth may provide one explanation for the success of $L$. polyphyllus as an invasive species in Finland.

We found negative trait associations, i.e. trade-offs, between alkaloid PC1 and resistance as well as between alkaloid PC1 and leaf trichomes among the native populations but not among the introduced ones. Alterations in trait associations based on population means, as we observed here, are an indication of divergent evolutionary processes among populations. Differences in trait associations between populations from the two countries suggest the existence of differential constraints on the evolution of these traits in the two places of origin. A lack of genetic variation may not limit trait evolution in the introduced area if there have been multiple introductions or if multiple origins were used in breeding the garden variety that has become naturalised. In plants, genetic diversity overall tends to be higher in introduced compared to native populations (Uller and Leimu 2011) and the population genetics of L. polyphyllus in Finland indicate the species originates from multiple introductions from different sources, predicting high genetic diversity (Li et al. 2016).

In Finland, post-introduction adaptation to the local generalist herbivores may have facilitated the spread of L. polyphyllus. The lack of strong negative trait associations suggests that the Finnish populations have been able to adapt and evolve in response to natural selection without many constraints. Although the patterns observed among the current populations cannot predict potential constraints or the lack thereof in the future, these results may help explain why $L$. polyphyllus has been successful in spreading and adapting to novel areas.

Acknowledgements We are grateful to Veera Hauhia and Suvi Hakulinen for their help in carrying out the experiments, USDA Forest Service for permission to collect seeds and the Ruissalo Botanical Garden for the use of their greenhouse facilities.

Authors contributions AK and SR conceived the research, and designed and executed the field work and common-garden experiments. NL and JP designed and conducted the chemical analyses. AK analysed the data and wrote the initial draft. All authors contributed substantially to revisions.

Funding Open access funding provided by University of Turku (UTU) including Turku University Central Hospital. This study was financially supported by the Turku Collegium for Science and Medicine (AK), the Academy of Finland (grants \#285746 and \#331046 to SR), the Finnish Cultural Foundation, $\mathrm{S}-\mathrm{W}$ Finland regional fund (grant to $\mathrm{AK}$ ), and the Turku University Foundation (grant to SR).

Availability of data and material Data will be archived in Dryad upon acceptance of the manuscript for publication.

\section{Declarations}

Conflict of interest Authors have no conflicts of interests to declare.

Open Access This article is licensed under a Creative Commons Attribution 4.0 International License, which permits use, sharing, adaptation, distribution and reproduction in any medium or format, as long as you give appropriate credit to the original author(s) and the source, provide a link to the Creative Commons licence, and indicate if changes were made. The images or other third party material in this article are included in the article's Creative Commons licence, unless indicated otherwise in a credit line to the material. If material is not included in the article's Creative Commons licence and your intended use is not permitted by statutory regulation or exceeds the permitted use, you will need to obtain permission directly from the copyright holder. To view a copy of this licence, visit http://creativecommons.org/licenses/by/4.0/.

\section{References}

Agrawal AA, Fishbein M, Jetter R et al (2009) Phylogenetic ecology of leaf surface traits in the milkweeds (Asclepias spp.): chemistry, ecophysiology, and insect behavior. New Phytol 183:848-867. https://doi.org/10.1111/j.1469-8137. 2009.02897.x

Agrawal AA, Hastings AP, Johnson MTJ et al (2012) Insect herbivores drive real-time ecological and evolutionary 
change in plant populations. Science 338:113-116. https:// doi.org/10.1126/science. 1225977

Alpert P, Bone E, Holzapfel C (2000) Invasiveness, invasibility and the role of environmental stress in the spread of nonnative plants. Perspect Plant Ecol Evol Syst 3:52-66. https://doi.org/10.1078/1433-8319-00004

Anderson MJ, Ellingsen KE, McArdle BH (2006) Multivariate dispersion as a measure of beta diversity. Ecol Lett 9:683-693. https://doi.org/10.1111/j.1461-0248.2006. 00926.x

Anstett DN, Chen W, Johnson MTJ (2016) Latitudinal gradients in induced and constitutive resistance against herbivores. J Chem Ecol 42:772-781. https://doi.org/10.1007/s10886016-0735-6

Armbruster WS, Schwaegerle KE (1996) Causes of covariation of phenotypic traits among populations. J Evol Biol 9:261-276. https://doi.org/10.1046/j.1420-9101.1996. 9030261.x

Arnold SJ (1992) Constraints on phenotypic evolution. Am Nat 140:S85-S107. https://doi.org/10.1086/285398

Bartón K (2020) MuMIn: multi-model inference. R package version 1.43 .17

Bates D, Maechler M, Bolker B, Walker S (2015) Fitting linear mixed-effects models using lme4. J Stat Softw 67:1-48. https://doi.org/10.18637/jss.v067.i01

Belsky AJ (1986) Does herbivory benefit plants? A review of the evidence. Am Nat 127:870-892. https://doi.org/10.1086/ 284531

Beuthin M (2012) Plant guide for bigleaf lupine (Lupinus polyphyllus). USDA-Natural Resources Conservation Service, Plant Materials Center, Corvallis, OR. Accessed 6 Jan 2021

Blossey B, Notzold R (1995) Evolution of increased competitive ability in invasive nonindigenous plants: a hypothesis. J Ecol 83:887-889. https://doi.org/10.2307/2261425

Burghardt KT (2016) Nutrient supply alters goldenrod's induced response to herbivory. Funct Ecol 30:1769-1778. https://doi.org/10.1111/1365-2435.12681

Buria H, Stahel W (1983) Altitudinal variation in Arianta arbustorum (Mollusca, Pulmonata) in the Swiss Alps. Genetica 62:95-108. https://doi.org/10.1007/BF00116631

Coley PD, Bryant JP, Chapin FS (1985) Resource availability and plant antiherbivore defense. Science 230:895-899. https://doi.org/10.1126/science.230.4728.895

Dawson W, Schrama M (2016) Identifying the role of soil microbes in plant invasions. J Ecol 104:1211-1218. https:// doi.org/10.1111/1365-2745.12619

Defossez E, Pitteloud C, Descombes P et al (2021) Spatial and evolutionary predictability of phytochemical diversity. Proc Natl Acad Sci U S A 118:e2013344118. https://doi. org/10.1073/pnas.2013344118

Doorduin LJ, Vrieling K (2011) A review of the phytochemical support for the shifting defence hypothesis. Phytochem Rev 10:99-106. https://doi.org/10.1007/s11101-010-91958

Ehleringer J, Bjorkman O, Mooney HA (1976) Leaf pubescence: effects on absorptance and photosynthesis in a desert shrub. Science 192:376-377. https://doi.org/10. 1126/science.192.4237.376

Feng YL, Lei YB, Wang RF et al (2009) Evolutionary tradeoffs for nitrogen allocation to photosynthesis versus cell walls in an invasive plant. Proc Natl Acad Sci USA 106:1853-1856. https://doi.org/10.1073/pnas.0808434106

Fremstad E (2010) NOBANIS—invasive alien species fact sheet Lupinus polyphyllus. In: Online Database Eur. Netw. Invasive Alien Species-NOBANIS

Futuyma DJ, Agrawal AA (2009) Macroevolution and the biological diversity of plants and herbivores. Proc Natl Acad Sci USA 106:18054-18061. https://doi.org/10.1073/pnas. 0904106106

Getman-Pickering ZL, Campbell A, Aflitto N et al (2020) LeafByte: a mobile application that measures leaf area and herbivory quickly and accurately. Methods Ecol Evol. https://doi.org/10.1111/2041-210X.13340

Glassmire AE, Philbin C, Richards LA et al (2019) Proximity to canopy mediates changes in the defensive chemistry and herbivore loads of an understory tropical shrub, Piper kelleyi. Ecol Lett 22:332-341. https://doi.org/10.1111/ele. 13194

Gloss AD, Nelson Dittrich AC, Goldman-Huertas B, Whiteman NK (2013) Maintenance of genetic diversity through plantherbivore interactions. Curr Opin Plant Biol 16:443-450. https://doi.org/10.1016/j.pbi.2013.06.002

Goldberg DE (1996) Competitive ability: definitions, contingency and correlated traits. Philos Trans R Soc B Biol Sci 351:1377-1385. https://doi.org/10.1098/rstb.1996.0121

Hahn PG, Agrawal AA, Sussman KI, Maron JL (2019) Population variation, environmental gradients, and the evolutionary ecology of plant defense against herbivory. Am Nat 193:20-34. https://doi.org/10.1086/700838

Hanley ME, Lamont BB, Fairbanks MM, Rafferty CM (2007) Plant structural traits and their role in anti-herbivore defence. Perspect Plant Ecol Evol Syst 8:157-178. https:// doi.org/10.1016/j.ppees.2007.01.001

Hawkes CV, Sullivan JJ (2001) The impact of herbivory on plants in different resource conditions: a meta-analysis. Ecology 82:2045-2058. https://doi.org/10.1890/00129658(2001)082[2045:TIOHOP]2.0.CO;2

Herms DA, Mattson WJ (1992) The dilemma of plants: to grow or defend. Q Rev Biol 67:283-335. https://doi.org/10. 1086/417659

Jonas CS, Geber MA (1999) Variation among populations of Clarkia unguiculata (Onagraceae) along altitudinal and latitudinal gradients. Am J Bot 86:333-343. https://doi.org/ $10.2307 / 2656755$

Joshi J, Vrieling K (2005) The enemy release and EICA hypothesis revisited: incorporating the fundamental difference between specialist and generalist herbivores. Ecol Lett 8:704-714. https://doi.org/10.1111/j.1461-0248.2005. 00769.x

Keane RM, Crawley MJ (2002) Exotic plant invasions and the enemy release hypothesis. Trends Ecol Evol 17:164-170. https://doi.org/10.1016/S0169-5347(02)02499-0

Kessler A, Kalske A (2018) Plant secondary metabolite diversity and species interactions. Annu Rev Ecol Evol Syst 49:115-138. https://doi.org/10.1146/annurev-ecolsys110617-062406

Kuznetsova A, Brockhoff PB, Christensen RHB (2017) lmerTest package: tests in linear mixed effects models. J Stat Softw 82:1-26. https://doi.org/10.18637/jss.v082.i13

Li SL, Vasemägi A, Ramula S (2016) Genetic variation and population structure of the garden escaper Lupinus 
polyphyllus in Finland. Plant Syst Evol 302:399-407. https://doi.org/10.1007/s00606-015-1273-3

Mauricio R, Rausher MD (1997) Experimental manipulation of putative selective agents provides evidence for the role of natural enemies in the evolution of plant defense. Evolution 51:1435-1444. https://doi.org/10.2307/2411196

Meier CI, Reid BL, Sandoval O (2013) Effects of the invasive plant Lupinus polyphyllus on vertical accretion of fine sediment and nutrient availability in bars of the gravel-bed Paloma river. Limnologica 43:381-387. https://doi.org/10. 1016/j.limno.2013.05.004

Müller-Schärer H, Schaffner U, Steinger T (2004) Evolution in invasive plants: implications for biological control. Trends Ecol Evol 19:417-422. https://doi.org/10.1016/j.tree.2004. 05.010

Muola A, Mutikainen P, Lilley M et al (2010) Associations of plant fitness, leaf chemistry, and damage suggest selection mosaic in plant-herbivore interactions. Ecology 91:2650-2659. https://doi.org/10.1890/09-0589.1

Oksanen J, Blanchet FG, Friendly M, Kindt R, Legendre P, McGlinn D, Minchin PR, O'Hara RB, Simpson GL,Solymos P, Stevens MHH, Szoecs E, Wagner H (2019) Vegan: community ecology package. $\mathrm{R}$ package version2.5-6. https://CRAN.R-project.org/package=vegan

Onoda Y, Hikosaka K, Hirose T (2004) Allocation of nitrogen to cell walls decreases photosynthetic nitrogen-use efficiency. Funct Ecol 18:419-425. https://doi.org/10.1111/j. 0269-8463.2004.00847.x

Poorter H, Niinemets Ü, Poorter L et al (2009) Causes and consequences of variation in leaf mass per area (LMA): a meta-analysis. New Phytol 182:565-588. https://doi.org/ 10.1111/j.1469-8137.2009.02830.x

Pothier J, Cheav SL, Galand N et al (1998) A comparative study of the effects of sparteine, lupanine and lupin extract on the central nervous system of the mouse. J Pharm Pharmacol 50:949-954. https://doi.org/10.1111/j.2042-7158.1998. tb04013.x

Ramula S, Pihlaja K (2012) Plant communities and the reproductive success of native plants after the invasion of an ornamental herb. Biol Invasions 14:2079-2090. https://doi. org/10.1007/s10530-012-0215-Z

Ramula S, Sorvari J (2017) The invasive herb Lupinus polyphyllus attracts bumblebees but reduces total arthropod abundance. Arthropod Plant Interact 11:911-918. https:// doi.org/10.1007/s11829-017-9547-z

Ramula S, Kalske A (2020) Introduced plants of Lupinus polyphyllus are larger but flower less frequently than conspecifics from the native range: results of the first year. Ecol Evol 10:13742-13751. https://doi.org/10.1002/ece3. 6964

Richards LA, Dyer LA, Forister ML et al (2015) Phytochemical diversity drives plant-insect community diversity. Proc Natl Acad Sci 112:10973-10978. https://doi.org/10.1073/ pnas. 1504977112

Sandquist DR, Ehleringer JR (2003) Population- and familylevel variation of brittlebush (Encelia farinosa, Asteraceae) pubescence: its relation to drought and implications for selection in variable environments. Am $\mathrm{J}$ Bot 90:1481-1486. https://doi.org/10.3732/ajb.90.10.1481

Schädler M, Jung G, Auge H, Brandl R (2003) Palatability, decomposition and insect herbivory: patterns in a successional old-field plant community. Oikos 103:121-132. https://doi.org/10.1034/j.1600-0706.2003.12659.x

Speiser B, Rowell-Rahier M (1991) Effects of food availability, nutritional value, and alkaloids on food choice in the generalist herbivore Arianta arbustorum (Gastropoda: Helicidae). Oikos 62:306-318. https://doi.org/10.2307/ 3545495

Terhivuo J (1978) Growth, reproduction and hibernation of Arianta arbustorum (L.) (Gastropoda, Helicidae) in southern Finland. Ann Zool Fennici 15:8-16

Tewes LJ, Müller C (2018) Syndromes in suites of correlated traits suggest multiple mechanisms facilitating invasion in a plant range-expander. NeoBiota 37:1-22. https://doi.org/ $10.3897 /$ neobiota. 37.21470

Toju H, Sota T (2006) Imbalance of predator and prey armament: geographic clines in phenotypic interface and natural selection. Am Nat 167:105-117. https://doi.org/10.1086/ 498277

Turcotte MM, Davies TJ, Thomsen CJM, Johnson MTJ (2014) Macroecological and macroevolutionary patterns of leaf herbivory across vascular plants. Proc R Soc B Biol Sci 281:20140555. https://doi.org/10.1098/rspb.2014.0555

Uller T, Leimu R (2011) Founder events predict changes in genetic diversity during human-mediated range expansions. Glob Chang Biol 17:3478-3485. https://doi.org/10. 1111/j.1365-2486.2011.02509.x

Valtonen A, Jantunen J, Saarinen K (2006) Flora and lepidoptera fauna adversely affected by invasive Lupinus polyphyllus along road verges. Biol Conserv 133:389-396. https://doi.org/10.1016/j.biocon.2006.06.015

Wink M (1984) Chemical defense of leguminosae. Are quinolizidine alkaloids part of the antimicrobial defense system of lupins? Zeitschrift Fur Naturforsch-J Biosci 39(10):548-552. https://doi.org/10.1515/znc-1984-0607

Wink M (1988) Plant breeding: importance of plant secondary metabolites for protection against pathogens and herbivores. Theor Appl Genet 75:225-233. https://doi.org/10. 1007/BF00303957

Wink M (2019) Quinolizidine and pyrrolizidine alkaloid chemical ecology - a mini-review on their similarities and differences. J Chem Ecol 45:109-115. https://doi.org/10. 1007/s10886-018-1005-6

Wink M, Witte L (1984) Turnover and transport of quinolizidine alkaloids. Diurnal fluctuations of lupanine in the phloem sap, leaves and fruits of Lupinus albus L. Planta 161:519-524. https://doi.org/10.1007/BF00407083

Woods EC, Hastings AP, Turley NE et al (2012) Adaptive geographical clines in the growth and defense of a native plant. Ecol Monogr 82:149-168. https://doi.org/10.1890/ 11-1446.1

Wright IJ, Cannon K (2001) Relationships between leaf lifespan and structural defences in a low-nutrient, sclerophyll flora. Funct Ecol 15:351-359. https://doi.org/10.1046/j.13652435.2001.00522.x 
Wright IJ, Reich PB, Westoby M et al (2004) The worldwide leaf economics spectrum. Nature 428:821-827. https://doi. org/10.1038/nature02403

Zhang Z, Pan X, Blumenthal D et al (2018) Contrasting effects of specialist and generalist herbivores on resistance evolution in invasive plants. Ecology 99:866-875. https://doi. org/10.1002/ecy.2155

Zheng YL, Feng YL, Zhang LK et al (2015) Integrating novel chemical weapons and evolutionarily increased competitive ability in success of a tropical invader. New Phytol 205:1350-1359. https://doi.org/10.1111/nph.13135

Publisher's Note Springer Nature remains neutral with regard to jurisdictional claims in published maps and institutional affiliations. 